\title{
Factors associated with modern contraceptive use among women with no fertility intention in sub-Saharan Africa: evidence from cross-sectional surveys of 29 countries
}

Bright Opoku Ahinkorah', Eugene Budu², Richard Gyan Aboagye ${ }^{3}$, Ebenezer Agbaglo ${ }^{4}$, Francis Arthur-Holmes ${ }^{5}$, Collins Adu ${ }^{6}$, Anita Gracious Archer ${ }^{7}$, Yaa Boahemaa Gyasi Aderojü and Abdul-Aziz Seidu ${ }^{2}, 9^{*}$ (D)

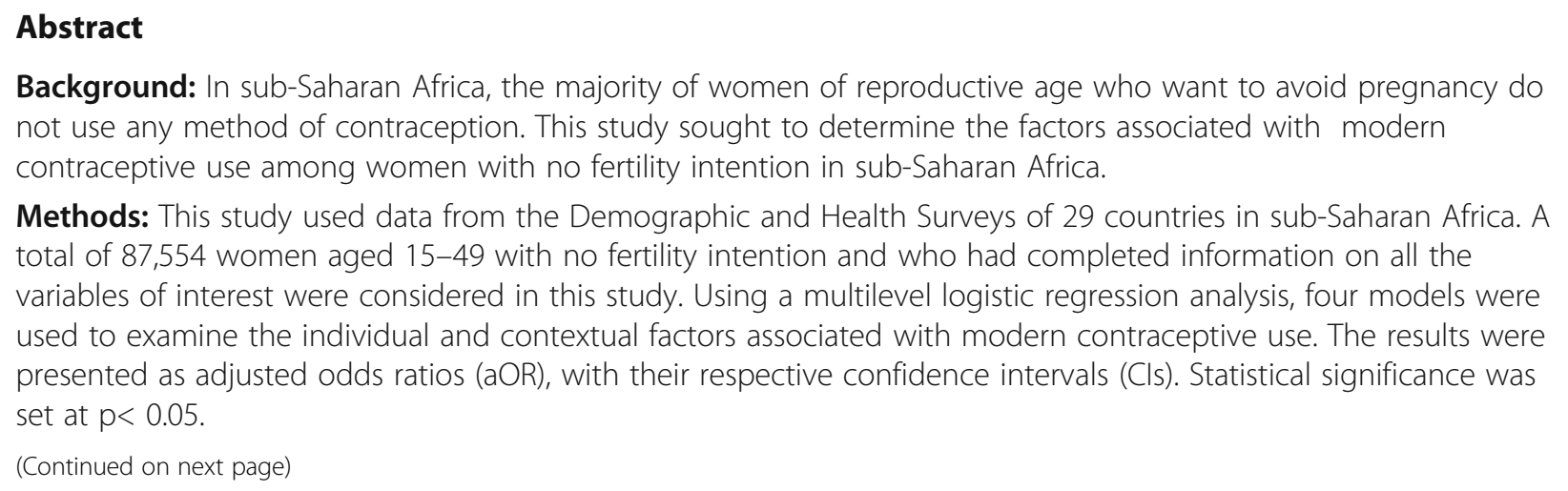

\footnotetext{
* Correspondence: abdul-aziz.seidu@stu.ucc.edu.gh

2Department of Population and Health, University of Cape Coast, Cape Coast,

Ghana

${ }^{9}$ College of Public Health, Medical and Veterinary Services, James Cook

University, Townsville, Australia

Full list of author information is available at the end of the article
}

(c) The Author(s). 2021 Open Access This article is licensed under a Creative Commons Attribution 4.0 International License, which permits use, sharing, adaptation, distribution and reproduction in any medium or format, as long as you give appropriate credit to the original author(s) and the source, provide a link to the Creative Commons licence, and indicate if changes were made. The images or other third party material in this article are included in the article's Creative Commons licence, unless indicated otherwise in a credit line to the material. If material is not included in the article's Creative Commons licence and your intended use is not permitted by statutory regulation or exceeds the permitted use, you will need to obtain permission directly from the copyright holder. To view a copy of this licence, visit http://creativecommons.org/licenses/by/4.0/. The Creative Commons Public Domain Dedication waiver (http://creativecommons.org/publicdomain/zero/1.0/) applies to the data made available in this article, unless otherwise stated in a credit line to the data. 
(Continued from previous page)

Results: The prevalence of modern contraceptive use was 29.6\%. With the individual-level factors, women aged 45-49 had lower odds of using modern contraceptives ( $\mathrm{aOR}=0.33,95 \% \mathrm{Cl}=0.28,0.39$ ). Women who had their first sex at age $15-19(\mathrm{aOR}=1.12,95 \% \mathrm{Cl}=1.07,1.17)$, those with higher education $(\mathrm{aOR}=1.93,95 \% \mathrm{Cl}=1.75,2.13)$, and women who were exposed to newspaper $(\mathrm{aOR}=1.15,95 \% \mathrm{Cl}=1.10,1.20)$ and radio $(\mathrm{aOR}=1.21,95 \% \mathrm{Cl}=1.17$, 1.26) had higher odds of modern contraceptive use. In terms of the contextual factors, women living in urban areas $(\mathrm{aOR}=1.06,95 \% \mathrm{Cl}=1.02,1.11)$, women in the richest wealth quintile $(\mathrm{aOR}=1.55,95 \% \mathrm{Cl}=1.43,1.67)$, and those in communities with medium literacy level ( $\mathrm{aOR}=1.11,95 \% \mathrm{Cl}=1.06,1.16)$ and medium community socio-economic status $(\mathrm{aOR}=1.17,95 \% \mathrm{Cl}=1.10,1.23)$ had higher odds of modern contraceptive use. Across the geographic regions in sub-Saharan Africa, women in Southern Africa had higher odds of modern contraceptive use (aOR $=5.29$, 95\% Cl=4.86, 5.76).

Conclusion: There is a relatively low prevalence of modern contraceptive use among women with no fertility intention in sub-Saharan Africa, with cross-country variations. Women's age, age at first sex, level of education, mass media exposure, place of residence, community literacy level and community socio-economic status were found to be associated with modern contraceptive use. It is, therefore, important for policy makers to consider these factors when designing and implementing programmes or policies to increase contraceptive use among women who have no intention to give birth. Also, policymakers and other key stakeholders should intensify mass education programmes to address disparities in modern contraceptive use among women.

Keywords: Fertility intention, modern contraceptives, sub-Saharan Africa, Women, Women's health

\section{Background}

To achieve target 3.7 of the Sustainable Development Goal (SDG) 3 which emphasizes that by 2030 the world should ensure universal access to sexual and reproductive healthcare services, utilization of modern contraceptive is key [1]. Report indicates that modern contraception prevented about 308 million unintended pregnancies in 2017 [2]. An additional 67 million unintended pregnancies could be averted if the needs for modern contraceptives are met [2]. Provision of modern contraception to women who want to avoid pregnancy could cause a reduction in maternal deaths from 308, 000 to 84,000 and newborn mortality from 2.7 million to 538,000 per year respectively [3]. These reductions in unintended pregnancies, and maternal and newborn mortalities can lead to the attainment of the target 3.1 and 3.2 of the SDG 3 which seek to reduce the global maternal mortality ratio to less than 70 per 100,000 live births and end all preventable deaths under 5 years of age by 2030 respectively [1].

Currently, about 1.9 billion women of reproductive age are living in the world. Of this number, 1.1 billion women need family planning [2, 4]. Only 842 million used modern contraceptives in 2019 [2, 4]. However, about 190 million women of reproductive age worldwide who want to avoid pregnancy do not use any contraceptive method, up from 156 million in 2000 [5]. In low-and middle-income countries, 214 million women who wanted to avoid pregnancy in 2019 were not using any method of contraception [2].

In sub-Saharan Africa (SSA), the majority of women of reproductive age who want to avoid pregnancy do not use any method of contraception [6]. Data from the United Nations Department of Economic and Social Affairs and Population Division [5] show that more than $20 \%$ of unmet need for family planning were in 15 countries in SSA. A study also reveals that 51 million women of reproductive age had an unmet need for modern contraceptive methods [4]. However, disparities exist in modern contraceptive utilization among women of reproductive age in SSA.

Evidence suggests that the prevalence of modern contraceptive usage among women of reproductive age in 2019 was high in both Estwatini and Namibia (both reporting $52 \%$ ) and low in Sudan (4\%) [5]. Among Ethiopian women, the prevalence of contraceptive use was 51.1\% [7]. Also, Gebrecherkos et al. [8] found a $41.8 \%$ prevalence of unmet need for modern contraception of which 31.8 and $10 \%$ represented the unmet need for spacing and limiting of birth respectively among women of reproductive age in Ethiopia. In Ghana, Wulifa et al. [9] found that $14.98 \%$ of the women had an unmet need for modern contraceptives. In Botswana, Letamo and Navaneetham [10] found the unmet need for family planning was reported to be 9.6\% among married women, $6.7 \%$ for spacing, and $2.9 \%$ for limiting. Despite the existing data on unmet needs for family planning, there is still a paucity of data on the magnitude of modern contraception among fecund women or women of reproductive age who do not have the desire to conceive a child in SSA.

Previous studies have suggested that cultural and religious myths and misconceptions undermine modern contraception [9, 11]. Other studies have highlighted that couple related factors (such as partner discussion, 
approval, and spousal decision making) [10, 12, 13], sociodemographic characteristics (age, educational status, religion, etc.) $[10,14]$, parity, exposure to mass media [14], knowledge on modern contraceptive methods [15], and fear of side effects [16] are associated with the utilization of modern contraceptives.

Although studies have recognized the importance of modern methods of contraception, few studies have been conducted to determine the factors associated with its utilization among women who have no intention to give birth to another child. This study sought to determine the factors associated with modern contraceptive use among women with no fertility intention in SSA. The findings from this study will provide evidence to inform decision-makers and stakeholders involved in family planning to improve women's access to sexual and reproductive health services, specifically, modern contraceptives in SSA.

\section{Methods \\ Study design}

Data for this study were obtained from the Demographic and Health Surveys (DHS) of 29 countries in SSA. For the purpose of the study, the women's recode files, which contain data on women aged 15-49 were used. The DHS is a nationally representative survey that is conducted in over 85 low- and middle-income countries and focuses on important men, maternal, and child health markers such as contraceptive use [17]. The survey employs a two-stage stratified sampling technique, which makes the data nationally representative. The study by Aliaga and Ruilin [18] provides details of the sampling process. A total of 87,544 women aged 15-49 who had no intention to give birth and had complete information on all the variables of interest in this study were considered. In this study, women with no fertility intention were those who responded "want no more," to the DHS question "would you like to have a (another) child with your husband/partner, or would you prefer not to have any more children with him?" We relied on the 'Strengthening the Reporting of Observational Studies in Epidemiology' (STROBE) statement in writing the manuscript [19]. The dataset is freely available for download at: https://dhsprogram.com/data/available-datasets. $\mathrm{cfm}$.

\section{Variables studied}

\section{Outcome variable}

The outcome variable for the study was current use of modern contraceptives among women with no fertility intention. We focused on women with no fertility intention as we expected that those category of women would be more likely to use contraceptives to prevent pregnancy. Hence, understanding the use of modern contraceptives among this cohort of women and the factors that drive them to use modern contraceptives is very crucial to reducing unwanted pregnancies and abortions. The variable, modern contraceptives, was derived from a question that elicited the types of contraceptives women with no fertility intention were using during the survey. Responses to this question were coded as "no method", "folkloric method", "traditional method" and "modern method". The modern methods included female sterilization, male sterilization, intrauterine device (IUD), injectables, and implants (Norplant). The modern methods also included contraceptive pill, condoms, emergency contraception, standard day method (SDM), vaginal methods (foam, jelly, suppository), and lactational amenorrhea method (LAM). Country-specific modern methods and other modern contraceptive methods (including cervical cap, contraceptive sponge, and others)which were mentioned by respondents were also regarded as modern contraceptives. Periodic abstinence (rhythm, calendar method), withdrawal (coitus interruptus) and country-specific traditional methods which are proven effectivewere considered as traditional methods. Locally described methods and spiritual methods (such as herbs, amulets, gris-gris, etc.) which are effective but not proven were the folkloric methods [17, 20, 21]. The existing DHS variable on contraceptive use did not include women who were pregnant, those who were infecund, and those who had never had sex. In this study, women using modern methods were coded as ' 1 ' while those who were not using any methods, those using traditional methods, and those using folkloric methods were recoded as ' 0 '.

\section{Independent variable}

Sixteen independent variables were considered in this study based on their significant associations with modern contraceptive use in previous studies [14, 22-24]. These variables have been broadly grouped into individual-level variables and contextual-level variables. The individual-level variables were age (15-19, 20-24, $25-29,30-34,35-39,40-44$ and $45-49$ years), marital status (never married, married, cohabiting, widowed and divorced), religion (Christianity, Islam, traditional and no religion), employment status (not working and working), age at first sex (less than 15 years, $15-19$ years and 20 years and above), parity (no birth, one birth, two births, three births, four or more births), level of education (no education, primary, secondary and higher), exposure to newspaper (no and yes), exposure to radio (no and yes), and exposure to television (no and yes).

The contextual-level variables were place of residence (urban and rural), wealth index (poorest, poorer, middle, richer and richest), community-level literacy-proportion of women who can read and write (low, medium and 


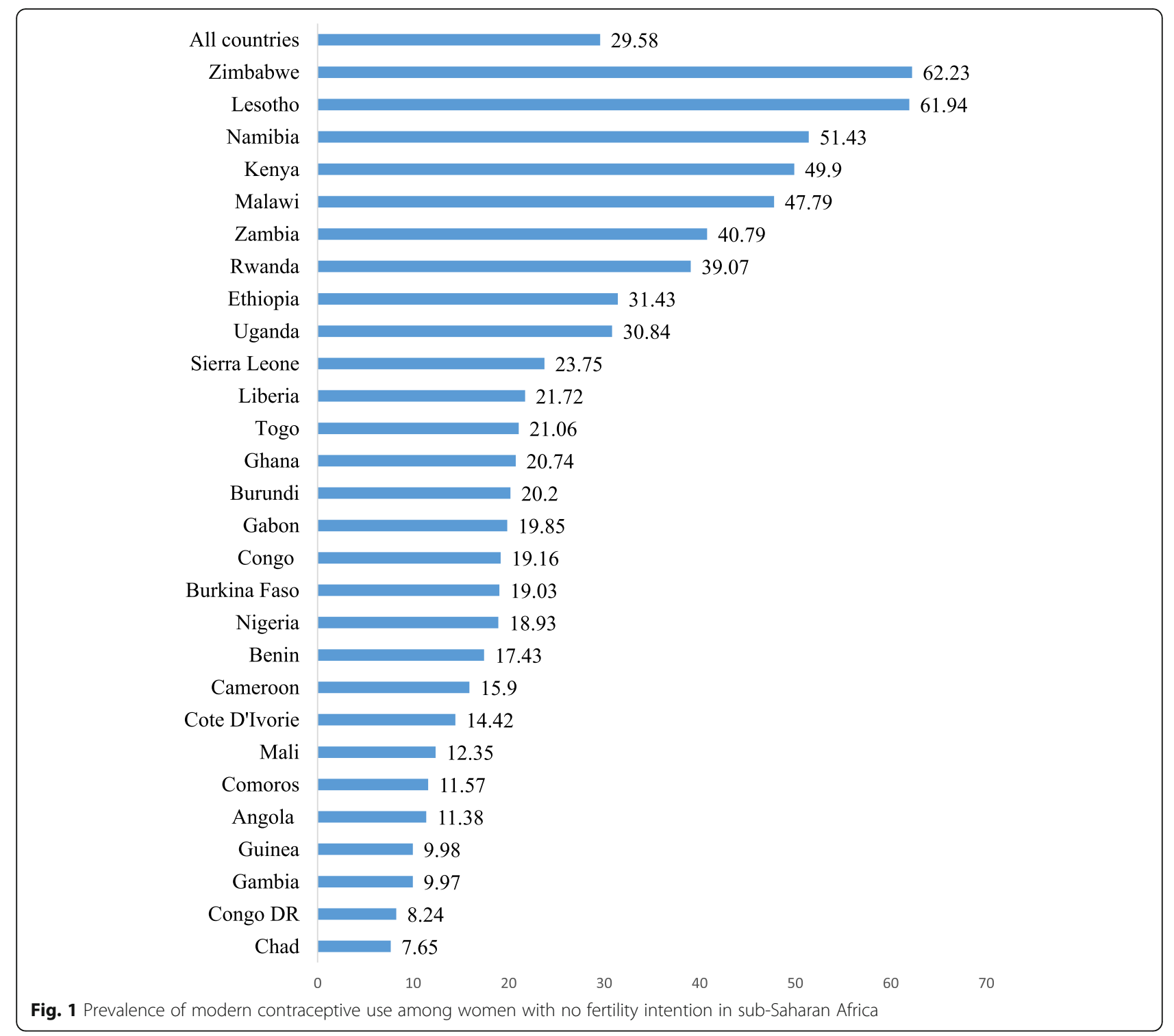

high), community-level socio-economic status - the proportion of women in the richest household quintile (low, medium and high), community knowledge of modern contraceptive method (low, medium and high), and subregion (West, East, Central and Southern). The countries in West Africa were Burkina Faso, Benin, Cote d'Ivoire, Ghana, Gambia, Guinea, Mali, Nigeria, Sierra Leone, Senegal, and Togo. Burundi, Cameroon, Ethiopia, Gabon, Kenya, Comoros, Malawi, Rwanda, Uganda, Zambia, and Zimbabwe were in East Africa. Angola, Congo DR, Congo, Liberia, and Chad were in Central Africa whiles Lesotho, and Namibia were in Southern Africa [25].

\section{Statistical analyses}

The data were analysed with Stata version 16.0. The analysis was conducted in three steps. The first step was the graphical representation of the prevalence of modern contraceptive use among women with no fertility intention in SSA. The second step was a bivariate analysis that calculated the proportion of modern contraceptive use across the explanatory variables with their $p$ values derived from a chi-square test of independence. To check for high correlation among the explanatory variables, a test for multicollinearity was carried out using the variance inflation factor (VIF) and the results showed no evidence of high collinearity (Mean VIF = 1.44, Maximum VIF $=2.15$, and Minimum VIF = 1.04). All the variables that showed statistical significance from the Table 2 were moved to the third step of the analysis. In the third step of the analysis, a multilevel logistic regression analysis comprising fixed effects and random effects was fitted. The results of the fixed effects of the model were presented as adjusted odds ratio (aOR) while the random effects were assessed with Intra-Cluster 
Correlation (ICC). Model comparison was done using the log-likelihood ratio (LLR) and Akaike's Information Criterion (AIC) tests. Four models were fitted in examining the individualand contextual-level factors associated with modern contraceptive use. The four models comprised an empty model (Model 0) which shows the variations in the use of modern contraceptives in the absence of any explanatory variable. Model I adjusted for the individual-level variables, Model II adjusted for the contextual-level variables and Model III adjusted for all the explanatory variables. Results were presented as adjusted odds ratios (aOR) at 95\% Confidence Interval. All frequency distributions were weighted (v005/1000000) while the survey command (SVY) in Stata was used to adjust for the complex sampling structure of the data in the regression analyses.

\section{Ethical approval}

The DHS reports that the DHS surveys have been reviewed and approved by Inner City Fund (ICF) Institutional Review Board (IRB) as well as Ethics Boards of partner organisations of the various countries such as the Ministries of Health. The DHS follows the standards for ensuring the protection of respondents' privacy. ICF International ensures that the survey complies with the U.S. Department of Health and Human Services' regulations for the respect of human subjects. This was a secondary analysis of data and therefore no further

Table 1 Description of the study sample

\begin{tabular}{|c|c|c|c|c|}
\hline Country & Year of survey & $\begin{array}{l}\text { Women aged } \\
15-49 \text { years }\end{array}$ & $\begin{array}{l}\text { Women with no fertlity intention who had } \\
\text { information on contraceptive use }\end{array}$ & $\begin{array}{l}\text { Women with } \\
\text { complete cases }\end{array}$ \\
\hline Angola & 2015-16 & 14,379 & 339 & 339 \\
\hline Burkina Faso & 2010 & 17,087 & 3419 & 3417 \\
\hline Benin & 2018 & 15,928 & 3178 & 3176 \\
\hline Burundi & 2016-17 & 17,269 & 5790 & 5787 \\
\hline Congo DR & 2013-14 & 18,827 & 3368 & 3366 \\
\hline Congo & $2011-12$ & 10,819 & 1458 & 1457 \\
\hline Cote D'Ivorie & $2011-12$ & 10,060 & 1365 & 1364 \\
\hline Cameroon & 2018 & 15,426 & 2928 & 2926 \\
\hline Ethiopia & 2016 & 15,683 & 4718 & 4715 \\
\hline Gabon & 2012 & 8422 & 1392 & 1391 \\
\hline Ghana & 2014 & 9396 & 2264 & 2263 \\
\hline Gambia & 2013 & 10,233 & 1071 & 1071 \\
\hline Guinea & 2012 & 10,874 & 1485 & 1484 \\
\hline Kenya & 2014 & 31,079 & 5318 & 5314 \\
\hline Comoros & 2012 & 5329 & 620 & 620 \\
\hline Liberia & 2013 & 9239 & 2001 & 2000 \\
\hline Lesotho & 2014 & 6621 & 3439 & 1716 \\
\hline Mali & 2018 & 10,424 & 1715 & 1714 \\
\hline Malawi & 2015-16 & 24,562 & 8237 & 8232 \\
\hline Nigeria & 2018 & 41,821 & 6931 & 6926 \\
\hline Namibia & 2013 & 10,018 & 2788 & 2786 \\
\hline Rwanda & 2014-15 & 13,497 & 4644 & 4641 \\
\hline Sierra Leone & 2013 & 16,658 & 1663 & 1662 \\
\hline Senegal & 2010-11 & 15,688 & 2266 & 2265 \\
\hline Chad & 2014-15 & 17,719 & 1753 & 1752 \\
\hline Togo & 2013-14 & 9480 & 2220 & 2219 \\
\hline Uganda & 2016 & 18,506 & 5483 & 5479 \\
\hline Zambia & 2018 & 13,683 & 4165 & 3978 \\
\hline Zimbabwe & 2015 & 9955 & 3496 & 3494 \\
\hline Total & & & 89,517 & 87,554 \\
\hline
\end{tabular}


Table 2 Distribution of modern contraceptive use by individual and contextual-level variables

\begin{tabular}{|c|c|c|c|c|}
\hline Variables & Weighted N & Weighted \% & Modern contraceptive & $\mathrm{p}$-values \\
\hline Age & & & & $<0.001$ \\
\hline $15-19$ & 2164 & 2.5 & 15.6 & \\
\hline $20-24$ & 4600 & 5.3 & 35.0 & \\
\hline $25-29$ & 9619 & 11.0 & 38.2 & \\
\hline $30-34$ & 15,430 & 17.6 & 37.9 & \\
\hline $35-39$ & 19,635 & 22.4 & 34.4 & \\
\hline $40-44$ & 19,234 & 22.0 & 27.0 & \\
\hline $45-49$ & 16,852 & 19.3 & 14.8 & \\
\hline Marital status & & & & $<0.001$ \\
\hline Never married & 5209 & 6.0 & 27.4 & \\
\hline Married & 57,118 & 65.2 & 32.2 & \\
\hline Cohabiting & 10,331 & 11.8 & 29.4 & \\
\hline Widowed & 3607 & 7.2 & 13.4 & \\
\hline Divorced & 8590 & 9.8 & 25.4 & \\
\hline Religion & & & & $<0.001$ \\
\hline Christianity & 64,891 & 74.1 & 33.9 & \\
\hline Islam & 19,161 & 21.9 & 16.9 & \\
\hline Traditional & 1914 & 2.2 & 15.0 & \\
\hline No religion & 1588 & 1.8 & 23.7 & \\
\hline Employment status & & & & 0.004 \\
\hline Not working & 17,988 & 20.5 & 29.0 & \\
\hline Working & 69,566 & 79.5 & 29.7 & \\
\hline Age at first sex & & & & $<0.001$ \\
\hline Less than 15 & 18,149 & 20.7 & 23.9 & \\
\hline 15-19years & 54,679 & 62.5 & 31.1 & \\
\hline 20 years and above & 14,726 & 16.8 & 31.0 & \\
\hline Parity & & & & $<0.001$ \\
\hline No birth & 1933 & 2.2 & 8.1 & \\
\hline One birth & 3867 & 4.4 & 25.5 & \\
\hline Two births & 8502 & 9.7 & 38.6 & \\
\hline Three births & 12,988 & 14.8 & 36.4 & \\
\hline Four or more births & 60,264 & 68.8 & 27.8 & \\
\hline Level of education & & & & $<0.001$ \\
\hline No education & 30,977 & 35.4 & 17.6 & \\
\hline Primary & 92,933 & 37.6 & 34.7 & \\
\hline Secondary & 20,324 & 23.2 & 37.5 & \\
\hline Higher & 3302 & 3.8 & 41.8 & \\
\hline Exposure to newspaper & & & & $<0.001$ \\
\hline No & 71,687 & 81.9 & 26.9 & \\
\hline Yes & 15,867 & 18.1 & 41.8 & \\
\hline Exposure to radio & & & & $<0.001$ \\
\hline No & 34,741 & 39.7 & 24.9 & \\
\hline Yes & 51,813 & 60.3 & 32.7 & \\
\hline
\end{tabular}


Table 2 Distribution of modern contraceptive use by individual and contextual-level variables (Continued)

\begin{tabular}{|c|c|c|c|c|}
\hline Variables & Weighted N & Weighted \% & Modern contraceptive & $p$-values \\
\hline \multicolumn{4}{|c|}{ Exposure to television } & \multirow[t]{3}{*}{$<0.001$} \\
\hline No & 54,414 & 62.1 & 27.5 & \\
\hline Yes & 33,140 & 37.9 & 33.0 & \\
\hline \multicolumn{4}{|l|}{ Residence } & \multirow[t]{3}{*}{$<0.001$} \\
\hline Urban & 30,434 & 34.8 & 32.4 & \\
\hline Rural & 57,120 & 65.2 & 28.1 & \\
\hline \multicolumn{5}{|l|}{ Wealth index } \\
\hline Poorest & 16,062 & 18.4 & 22.1 & \multirow[t]{5}{*}{$<0.001$} \\
\hline Poorer & 17,170 & 19.6 & 26.7 & \\
\hline Middle & 17,582 & 20.1 & 29.4 & \\
\hline Richer & 18,341 & 20.9 & 32.1 & \\
\hline Richest & 18,399 & 21.0 & 36.5 & \\
\hline \multicolumn{4}{|c|}{ Community literacy level } & \multirow[t]{4}{*}{$<0.001$} \\
\hline Low & 33,855 & 38.7 & 24.5 & \\
\hline Medium & 29,145 & 33.4 & 35.9 & \\
\hline High & 24,554 & 28.0 & 29.1 & \\
\hline \multicolumn{4}{|c|}{ Community socioeconomic status } & \multirow[t]{4}{*}{$<0.001$} \\
\hline Low & 47,293 & 54.0 & 25.4 & \\
\hline Medium & 10,087 & 11.5 & 36.0 & \\
\hline High & 30,174 & 34.5 & 34.0 & \\
\hline \multicolumn{4}{|c|}{ Community knowledge of modern contraceptive method } & \multirow[t]{3}{*}{$<0.001$} \\
\hline Low & 81,646 & 93.3 & 30.9 & \\
\hline Medium & 5908 & 6.7 & 11.9 & \\
\hline \multicolumn{4}{|l|}{ Sub-region } & \multirow[t]{5}{*}{$<0.001$} \\
\hline West Africa & 27,561 & 31.5 & 17.7 & \\
\hline East Africa & 46,577 & 53.2 & 37.3 & \\
\hline Central Africa & 8914 & 10.2 & 13.1 & \\
\hline Southern Africa & 4502 & 5.1 & 55.4 & \\
\hline
\end{tabular}

NB: $p$-values obtained from chi-square test

approval was required since the data is available in the public domain. Further information about the DHS data usage and ethical standards are available at http://goo.gl/ ny8T6X (Table 1).

\section{Results}

Prevalence of modern contraceptive use among women with no fertility intention in sub-Saharan Africa

Figure 1 shows the prevalence of modern contraceptive use among women with no fertility intention in 29 subSaharan African countries. The overall prevalence of modern contraceptive use among women with no fertility intention in the 29 sub-Saharan African countries considered in this study was $29.6 \%$. In terms of countrybased analysis, Zimbabwe (62.2\%) had the highest prevalence of modern contraceptive use while Chad (7.7\%) had the lowest prevalence.
Distribution of modern contraceptive use by individualand contextual-level variables

Table 2 shows the distribution of modern contraceptive use among women with no fertility intention by individual and contextual variables. With the individual-level factors, the highest prevalence of modern contraceptive use was found among women aged 25-29 (38.2\%), married women (32.2\%), Christians (33.9\%), working women (29.7\%), those who had their first sex when they were 15-19 years (31.1\%), women with two births (38.6\%), those with higher level of education (41.8\%), and women with exposure to newspaper (41.8\%), radio (32.7\%), and television (33\%). In terms of the contextual-level factors, the highest prevalence of modern contraceptive use was found among women in urban areas (32.4\%), those in the richest wealth quintile $(36.5 \%)$, women in communities with medium community literacy levels (35.9\%), 
Table 3 Mixed-effects results on the predictors of modern contraceptive use among women with no fertility intention in subSaharan Africa

\begin{tabular}{|c|c|c|c|c|}
\hline Variables & Model 0 & $\begin{array}{l}\text { Model I } \\
\text { aOR(95\%Cl) }\end{array}$ & $\begin{array}{l}\text { Model II } \\
\text { aOR(95\%CI) }\end{array}$ & $\begin{array}{l}\text { Model III } \\
\text { aOR(95\%Cl) }\end{array}$ \\
\hline \multicolumn{5}{|l|}{ Age } \\
\hline $15-19$ & & 1 & & 1 \\
\hline $20-24$ & & $1.20^{*}(1.04-1.40)$ & & $1.03(0.88-1.20)$ \\
\hline $25-29$ & & $1.26^{* *}(1.08-1.46)$ & & $0.95(0.81-1.17)$ \\
\hline $30-34$ & & $1.26^{* *}(1.08-1.47)$ & & $0.92(0.78-1.08)$ \\
\hline $35-39$ & & $1.13(0.74-1.32)$ & & $0.86(0.73-1.01)$ \\
\hline $40-44$ & & $0.86(0.74-1.01)$ & & $0.66^{* * *}(0.56-0.78)$ \\
\hline $45-49$ & & $0.43^{* * *}(0.37-0.50)$ & & $0.33^{* * * *}(0.28-0.39)$ \\
\hline \multicolumn{5}{|l|}{ Marital status } \\
\hline Married & & 1 & & 1 \\
\hline Not married & & $0.72^{* * *}(0.66-0.77)$ & & $0.59^{* * *}(0.55-0.65)$ \\
\hline Cohabiting & & $0.61^{* * *}(0.58-0.64)$ & & $0.73^{* * *}(0.69-0.76)$ \\
\hline Widowed & & $0.34^{* * *}(0.31-0.37)$ & & $0.31^{* * *}(0.28-0.33)$ \\
\hline Divorced & & $0.56^{* * *}(0.53-0.60)$ & & $0.55^{* * *}(0.52-0.59)$ \\
\hline \multicolumn{5}{|l|}{ Religion } \\
\hline Christianity & & 1 & & 1 \\
\hline Islam & & $0.53^{* * *}(0.50-0.55)$ & & $0.60^{* * *}(0.57-0.63)$ \\
\hline Traditional & & $0.51^{* * *}(0.44-0.57)$ & & $0.78^{* * *}(0.69-0.89)$ \\
\hline No religion & & $0.72^{* * *}(0.64-0.81)$ & & $0.81^{* * *}(0.75-0.91)$ \\
\hline \multicolumn{5}{|l|}{ Employment status } \\
\hline Working & & 1 & & 1 \\
\hline Not working & & $1.00(0.96-1.04)$ & & $0.89^{* * *}(0.85-0.93)$ \\
\hline \multicolumn{5}{|l|}{ Age at first sex } \\
\hline Less than 15 & & 1 & & 1 \\
\hline $15-19$ & & $1.23^{* * *}(1.18-1.28)$ & & $1.12^{* * *}(1.07-1.17)$ \\
\hline $20+$ & & $1.15^{* * *}(1.09-1.22)$ & & $0.96(0.91-1.02)$ \\
\hline \multicolumn{5}{|l|}{ Parity } \\
\hline No birth & & 1 & & 1 \\
\hline One birth & & $3.41^{* * *}(2.81-4.14)$ & & $3.66^{* * *}(3.00-4.48)$ \\
\hline Two births & & $6.13^{* * *}(5.03-7.47)$ & & $7.59^{* * *}(6.18-9.32)$ \\
\hline Three births & & $6.30^{* * *}(5.16-7.70)$ & & $8.85^{* * *}(7.19-10.90)$ \\
\hline Four or more births & & $5.55^{* * *}(4.54-6.77)$ & & $8.78^{* * *}(7.13-10.82)$ \\
\hline \multicolumn{5}{|l|}{ Education } \\
\hline No education & & 1 & & 1 \\
\hline Primary & & $1.96^{* * *}(1.88-2.05)$ & & $1.56^{* * *}(1.49-1.63)$ \\
\hline Secondary & & $2.05^{* * *}(1.95-2.16)$ & & $1.75^{* * *}(1.65-1.85)$ \\
\hline Higher & & $2.23^{* * *}(2.03-2.45)$ & & $1.93^{* * *}(1.75-2.13)$ \\
\hline \multicolumn{5}{|c|}{ Exposure to newspaper } \\
\hline No & & 1 & & 1 \\
\hline Yes & & $1.40^{* * *}(1.34-1.46)$ & & $1.15^{* * *}(1.10-1.20)$ \\
\hline \multicolumn{5}{|l|}{ Exposure to radio } \\
\hline No & & 1 & & 1 \\
\hline Yes & & $1.31^{* * *}(1.26-1.35)$ & & $1.21^{* * *}(1.17-1.26)$ \\
\hline
\end{tabular}


Table 3 Mixed-effects results on the predictors of modern contraceptive use among women with no fertility intention in subSaharan Africa (Continued)

\begin{tabular}{|c|c|c|c|c|}
\hline Variables & Model 0 & $\begin{array}{l}\text { Model I } \\
\text { aOR(95\%Cl) }\end{array}$ & $\begin{array}{l}\text { Model II } \\
\text { aOR(95\%Cl) }\end{array}$ & $\begin{array}{l}\text { Model III } \\
\text { aOR(95\%Cl) }\end{array}$ \\
\hline \multicolumn{5}{|l|}{ Exposure to television } \\
\hline No & & 1 & & 1 \\
\hline Yes & & $0.97(0.93-1.01)$ & & $0.98(0.94-1.02)$ \\
\hline \multicolumn{5}{|l|}{ Residence } \\
\hline Rural & & & 1 & 1 \\
\hline Urban & & & $1.05^{*}(1.01-1.10)$ & $1.06^{* *}(1.02-1.11)$ \\
\hline \multicolumn{5}{|l|}{ Wealth index } \\
\hline Poorest & & & 1 & 1 \\
\hline Poorer & & & $1.36^{* * *}(1.39-1.43)$ & $1.26^{* * *}(1.19-1.33)$ \\
\hline Middle & & & $1.53^{* * *}(1.45-1.61)$ & $1.34^{* * *}(1.27-1.41)$ \\
\hline Richer & & & $1.70^{* * *}(1.61-1.80)$ & $1.44^{* * *}(1.35-1.52)$ \\
\hline Richest & & & $1.99^{* * *}(1.86-2.13)$ & $1.55^{* * *}(1.43-1.67)$ \\
\hline \multicolumn{5}{|l|}{ Community literacy level } \\
\hline Low & & & 1 & 1 \\
\hline Medium & & & $1.27^{* * * *}(1.23-1.32)$ & $1.11^{* * *}(1.06-1.16)$ \\
\hline High & & & $1.12^{* * *}(1.07-1.17)$ & $0.95(0.90-1.00)$ \\
\hline \multicolumn{5}{|c|}{ Community socioeconomic status } \\
\hline Low & & & 1 & 1 \\
\hline Medium & & & $1.14^{* * *}(1.08-1.20)$ & $1.17^{* * *}(1.10-1.23)$ \\
\hline High & & & $1.06^{*}(1.01-1.12)$ & $1.13^{* * *}(1.07-1.19)$ \\
\hline \multicolumn{5}{|c|}{ Community knowledge of modern contraceptive method } \\
\hline Low & & & 1 & 1 \\
\hline Medium & & & $0.77^{* * *}(0.70-0.84)$ & $0.81^{* * *}(0.74-0.89)$ \\
\hline \multicolumn{5}{|l|}{ Sub-region } \\
\hline West Africa & & & 1 & 1 \\
\hline East Africa & & & $2.62^{* * *}(2.52-2.72)$ & $2.16^{* * *}(2.07-2.27)$ \\
\hline Central Africa & & & $0.66^{* * *}(0.62-0.72)$ & $0.57^{* * *}(0.52-0.62)$ \\
\hline Southern Africa & & & $5.08^{* * * *}(5.08-5.85)$ & $5.29^{* * *}(4.86-5.76)$ \\
\hline \multicolumn{5}{|l|}{ Random effect result } \\
\hline PSU variance $(95 \% \mathrm{Cl})$ & $0.03(0.02-0.04)$ & $0.02(0.02-0.03)$ & $0.02(0.02-0.03)$ & $0.02(0.01-0.03)$ \\
\hline ICC & 0.009398 & 0.0073918 & 0.0066778 & 0.0059027 \\
\hline LR Test & Chi-square $=93.90, p<0.0001$ & Chi-square $=60.28, p<0.0001$ & Chi-square $=52.94, p<0.0001$ & Chi-square $=39.24, p<0.0001$ \\
\hline Wald chi-square & Reference & $8014.01^{* * *}$ & $6928.45^{* * *}$ & $11,041.57^{* * *}$ \\
\hline \multicolumn{5}{|l|}{ Model fitness } \\
\hline Log-likelihood & $-52,079.447$ & $-47,165.892$ & -48.68 .293 & $-44,895.43$ \\
\hline AlC & $104,162.9$ & $94,387.78$ & $96,166.59$ & $89,872.86$ \\
\hline N & 87,554 & 87,554 & 87,554 & 87,554 \\
\hline Number of clusters & 1605 & 1605 & 1605 & 1605 \\
\hline
\end{tabular}

Exponentiated coefficients; $95 \%$ confidence intervals in brackets

${ }^{*} p<0.05,{ }^{* *} p<0.01,{ }^{* * *} p<0.001$,

$1=$ Reference category; ICC = Intra-Class Correlation; AIC = Akaike's Information Criterion;

Model $0=$ The null model, a baseline model without any determinant variable

Model I = Individual-level variables

Model II = Contextual-level variables

Model III = The final model adjusted for individual - and contextual-level variables 
and socio-economic status (36.0\%), those in communities with low knowledge of modern contraceptives (30.9\%), and those who lived in Southern Africa (55.4\%). The chisquare test results showed statistically significant associations between all the individual and contextual variables and modern contraceptive use.

Factors associated with modern contraceptive use among women with no fertility intention in sub-Saharan Africa Measures of association (fixed effects)

Table 3 shows the results of the multilevel logistic regression analyses on the association between modern contraceptive use among women with no fertility intention and the individual- and contextual-level variables. With the individual-level factors, women aged 4549 had lower odds of using modern contraceptive (aOR $=0.33,95 \% \mathrm{CI}=0.28,0.39)$ compared to those aged 15-19. Compared to married women, women who were never married, cohabiting, widowed or divorced were less likely to use modern contraceptives. The odds of modern contraceptive use decreased among Muslims, Traditionalists, and women with no religion compared to Christians. Women who were not working were less likely to use modern contraceptives compared to those who were working $(\mathrm{aOR}=0.89,95 \% \mathrm{CI}=0.85,0.93)$. Compared to women who had their first sex at the age below 15, those who had their first sex at age 15-19 were more likely to use modern contraceptives $(\mathrm{aOR}=$ 1.12 , 95\% CI $=1.07,1.17$ ). Women with four or more births were more likely to use modern contraceptives compared to those with no birth $(\mathrm{aOR}=8.79,95 \%$ $\mathrm{CI}=7.13$, 10.82). The likelihood of modern contraceptive use also increased with the level of education with the highest likelihood among those with higher education compared to those with no formal education $(\mathrm{aOR}=1.93,95 \% \mathrm{CI}=1.75,2.13)$. Women who were exposed to newspaper $(\mathrm{aOR}=1.15,95 \% \mathrm{CI}=$ $1.10,1.20)$ and radio $(\mathrm{aOR}=1.21,95 \% \mathrm{CI}=1.17,1.26)$ had higher odds of modern contraceptive use compared to those who were not.

In terms of contextual factors, women in communities with medium knowledge of modern contraceptive method $(\mathrm{aOR}=0.81,95 \% \mathrm{CI}=0.75,0.89)$ were less likely to use modern contraceptives. Conversely, women in urban areas $(\mathrm{aOR}=1.06,95 \% \mathrm{CI}=1.02$, $1.11)$, women with richest wealth quintile $(\mathrm{aOR}=1.55$, 95\% CI $=1.43,1.67$ ), those in communities with medium literacy level $(\mathrm{aOR}=1.11,95 \% \mathrm{CI}=1.06$, 1.16) and medium community socio-economic status ( $\mathrm{aOR}=1.17,95 \% \mathrm{CI}=1.10,1.23)$ had higher odds of modern contraceptive use. Across the geographic regions in SSA, Southern Africa had higher odds of modern contraceptive use $(\mathrm{aOR}=5.29,95 \% \mathrm{CI}=4.86$, 5.76) compared to those in West Africa.

\section{Measures of variation (random effects)}

The results of the random effects on the association between modern contraceptive use among women with no fertility intention and the individual and contextual variables show variations in all the models. In Model 0, the clustering of the primary sampling units (PSUs) accounted for significant variations in the odds of modern contraceptive use $(\sigma 2=0.03,95 \%$ CI $0.02-0.04)$. Model 0 showed that $0.9 \%$ of the total variation in modern contraceptive use was attributed to the variance between clusters (ICC $=0.0093)$. The between-cluster variance was slightly smaller $(\mathrm{ICC}=0.0079)$ in Model I (with individual-level factors only). From Model I, the ICC decreased in Model II (contextual level only model) $(\mathrm{ICC}=0.0072)$. It then increased in Model III (ICC = $0.0067)$ where all the independent variables (both individual and contextual variables) were considered. This indicates that differences in the clustering of the PSUs account for the variations in modern contraceptive use. The highest log- likelihood $(-44,895.43)$ and the lowest AIC $(89,872.86)$ were used to determine the best fit model (Table 3).

\section{Discussion}

In this study, we investigated the prevalence and correlates of modern contraceptive use among women with no fertility intention in SSA. We found the overall prevalence of modern contraceptive use among the selected women to be $29.6 \%$. This low prevalence suggests that the use of modern contraceptives for fertility prevention is still a problem among women in SSA. In terms of country-based analysis, Zimbabwe (62.2\%) had the highest prevalence of modern contraceptive use followed by Lesotho (7.7\%). Chad (7.7\%) had the lowest prevalence of modern contraceptive use. This finding agrees with that of Yaya et al. (2018), who reported low contraceptive use in several sub-Saharan African countries, including Chad. However, Chikandiwa et al. [26] reported higher use of modern contraception among Zimbabwean women than Kenyan women. In explaining this finding, a study in Zimbabwe showed that over the years, the post-independence Zimbabwean government had encouraged women to use contraceptives, hence resulting in high prevalance of contraceptives among Zimbabwean women [27]. Women aged 45-49 had lower odds of using modern contraceptives compared to those aged 15-19. This finding resonates with that of Adebowale et al. [28]. The lower contraceptive use might be because women aged 15-19 are still in school and as a result might not want to have children to interrupt their academic activities [28]. Another reason could be that younger women (age 15-19) are highly sexually active and had to use modern contraceptives to prevent unwanted pregnancies [29]. Relatedly, women who were 
never married, cohabiting women, widows, and divorcees were less likely to use modern contraceptives compared to married women. The reason could be that women with no births and those with few births were sexually active and fertile, which demanded that they used more contraceptives to prevent pregnancies. On the other hand, widowed women and divorcees might not be in any sexual relationship, therefore resulting in their low use of modern contraceptives.

With mass media exposure, women who were exposed to newspaper and radio had higher odds of modern contraceptive use, compared to those who were not. This finding highlights the role of mass media in spreading information regarding family planning. Previous studies in Ethiopia [30] and Nigeria [31], as well as Burkina Faso and Senegal [32] have reported the effectiveness of mass media messages in promoting contraceptive use. Ownership of a radio and exposure to family planning radio messages independently encourage women to use modern methods of contraception [33]. This findings therefore suggest the need for sub-Saharan African countries to use mass media as a channel to spread information regarding the use of modern contraceptives to women. This has a capacity to increase contraceptive use among women with no fertility intention.

The odds of modern contraceptive use decreased among Muslims, Traditionalists and women with no religion compared to Christians. A negative relationship between Muslim women and family planning use has been reported by previous studies [34, 35]. Our finding agrees with previous studies conducted in Ethiopia [36, 37], Nigeria [28, 34, 35] and Ghana [38]. The reason for this might be that religious resistance for contraceptive uptake may be more pronounced in Islam than other religions [7, 39]. A study by Hani et al. [40] revealed a strong opposition by husband to the use of contraceptive. This was found as a reason for non-use of contraceptives among Muslim women. As Hani et al. [40] suggested, participation of husband in counseling and involvement of religious leaders in decisions on contraceptive use could improve its use among Muslim women.

Consistent with previous studies in Ethiopia [37], Malawi [41], and Ghana [42], this study recorded lower odds of modern contraceptives use among women who were not working. In most sub-Saharan African countries, contraceptive access is not completely free. At health facilities, levies are charged. Apart from this, distance from family planning clinics is considered as far for most women, particularly those from rural communities. Even in urban areas, family planning clinics are not evenly situated. Transportation cost becomes a barrier to utilization of family planning services [28]. Women need some level of financial autonomy to be able to purchase and use modern contraceptives.
Whereas working women may be able to cater for the cost involved in using modern contraceptives, their counterparts who are not working may not [37, 41, 42]. Women who are engaged in occupations that disallow frequent maternity leaves might cause them to use contraceptives.

Moreover, we recorded lower odds of modern contraceptives use among women living in rural areas, and those with medium community knowledge of modern contraceptive method. Similarly, Adebowale et al. [28] reported lower use of modern contraceptives among women with no fertility intention in rural areas in Nigeria. As noted by Asresie et al. [7], inadequate access to family planning service is one of the predominant reasons for the non-use of contraceptives. Thus, the lower use of modern contraceptives among inhabitants of rural areas may be attributed to poor access or unavailability of health facilities in rural areas. Other reasons for low use of modern contraceptives in rural areas could be poor spousal communication, sociocultural norms (especially the husband's role as the primary decision-maker), fear of side-effects and a lack of knowledge [43]. This finding highlights the need for development of programs to increase contraceptive use among women with no fertility intention while taking into consideration the rural-urban disparities.

Finally, we found level of education and community literacy to be significantly associated with the use of modern contraceptives among the study participants. As Nyarko [42] emphasized, well-educated people have contraceptive advantages in two ways. First, their level of education can provide them with accurate knowledge about contraception, contraceptive methods and their benefits. Second, their period of education may encourage them to use modern contraceptive methods to avoid getting pregnant while in school. In terms of community literacy, our study agrees with the findings of Ahinkorah [22], who reported low use of modern contraceptives use among women living in communities with low literacy in SSA. Our study also showed that women in the richest wealth quintile and those in communities with middle socioeconomic status recorded higher odds of modern contraceptives utilization. The use of contraceptives comes with its associated financial burden. While richest women may be in the position to skip any financial hurdles to the use of modern contraceptives, poor women may not $[21,22]$.

\section{Strengths and limitations}

The main strength of this study lies in the use of nationally representative data of each of the countries represented in the study. With this, the findings are generalizable to all women in the countries studied. Another strength lies in the use of sophisticated data collection methods, with experienced field assistants, which generated a higher response rate. We also employed 
higher order statistical tools for the analysis, which ensured rigorous analysis of the data. Despite these strengths, the study has some limitations that need to be acknowledged. First, with the cross-sectional research approach adopted, we cannot make causal inferences among the studied variables. Also, given the retrospective nature of reporting that characterizes demographic data, the data are likely to be subjected to recall biases. Relatedly, issues of social desirability bias may also be present.

\section{Conclusion}

There is a relatively low prevalence of modern contraceptive use among women with no fertility intention in sub-Saharan Africa, with cross-country variations. Women's age, age at first sex, level of education, mass media exposure, religion, employment status, place of residence, community literacy level and community socio-economic status were found to be associated with modern contraceptive use.. It is, therefore, important for policy makers policies to consider these factors when designing and implementing programmes or policies take to increase contraceptive use among women who have no intention to give birth. Also, policymakers and other key stakeholders should intensify mass education programmes to address disparities in modern contraceptive use among women. Such education programmes should target both rural and urban communities to increase women's knowledge and use of modern contraceptives.

\section{Abbreviations}

aOR: Adjusted Odds Ratio; Cl: Confidence Interval; GDHS: Ghana Demographic and Health Survey; DHS: Demographic and Health Survey; PHC: Population and Housing Census; NHIS: National Health Insurance Scheme

\section{Acknowledgements}

We acknowledge Measure DHS for providing us with the data.

\section{Authors' contributions}

$B O A, E B$ and $A S$ conceived the study. BOA, EB and AS analysed the data. FA$\mathrm{H}$ intepreted the results. BOA,EB, RA,EA,FA-H,CA,AGA,YBGA and AS drafted the manuscript. All authors reviewed and approved the final version of the manuscript.

\section{Authors' information}

School of Public Health, Faculty of Health, University of Technology Sydney, Sydney, Australia (BOA), Department of Population and Health, University of Cape Coast, Cape Coast, Ghana (EB, AS), School of Public Health, University of Health and Allied Sciences, Ho, Ghana (RA), Department of English, University of Cape Coast, Cape Coast, Ghana (EA), Department of Sociology and Social Policy, Lingnan University, 8 Castle Peak Road, Tuen Mun, Hong Kong (FA-H), Department of Health Promotion, Education and Disability Studies, Kwame Nkrumah University of Science and Technology, Kumasi, Ghana (CA); School of Nursing and Midwifery, University of Health and Allied Sciences, Ho, Ghana (AGA), Department of Adult Health Nursing, School of Nursing and Midwifery, University of Cape Coast, Cape Coast, Ghana (YBGA), College of Public Health, Medical and Veterinary Services, James Cook University, Australia (AS).

\section{Funding}

This research did not receive any specific grant from funding agencies in the public, commercial, or not-for-profit sectors.

\section{Availability of data and materials}

The dataset is freely available for download at: https://dhsprogram.com/data/ available-datasets.cfm.

\section{Declarations}

\section{Ethics approval and consent to participate}

The DHS reports that the DHS surveys have been reviewed and approved by Inner City Fund (ICF) Institutional Review Board (IRB) as well as Ethics Boards of partner organisations of the various countries such as the Ministries of Health. The DHS follows the standards for ensuring the protection of respondents' privacy. ICF International ensures that the survey complies with the U.S. Department of Health and Human Services' regulations for the respect of human subjects. This was a secondary analysis of data and therefore no further approval was required since the data is available in the public domain. Further information about the DHS data usage and ethical standards are available at http://goo.gl/ny8T6X.

\section{Consent for publication}

Not applicable.

\section{Competing interests}

The authors declare that they have no competing interests.

\section{Author details}

'School of Public Health, Faculty of Health, University of Technology Sydney, Sydney, Australia. ${ }^{2}$ Department of Population and Health, University of Cape Coast, Cape Coast, Ghana. ${ }^{3}$ School of Public Health, University of Health and Allied Sciences, Ho, Ghana. ${ }^{4}$ Department of English, University of Cape Coast, Cape Coast, Ghana. ${ }^{5}$ Department of Sociology and Social Policy, Lingnan University, 8 Castle Peak Road, Tuen Mun, Hong Kong. ${ }^{6}$ Department of Health Promotion, Education and Disability Studies, Kwame Nkrumah University of Science and Technology, Kumasi, Ghana. ${ }^{7}$ School of Nursing and Midwifery, University of Health and Allied Sciences, Ho, Ghana. ${ }^{8}$ Department of Adult Health Nursing, School of Nursing and Midwifery, University of Cape Coast, Cape Coast, Ghana. ${ }^{9}$ College of Public Health, Medical and Veterinary Services, James Cook University, Townsville, Australia.

Received: 10 February 2021 Accepted: 28 April 2021

Published online: 01 August 2021

\section{References}

1. World Health Organization. World Health Statistics 2018: monitoring health for the SDGs, Sustainable Development Goals: World Health Organization; 2018.

2. World Health Organization. WHO recommendations on self-care interventions: Self-administration of injectable contraception (No. WHO/ SRH/20.9): World Health Organization; 2020.

3. Darroch JE, Sully E, Biddlecom A. Adding it up: investing in contraception and maternal and newborn health, 2017-supplementary tables. New York, NY: The Guttmacher Institute; 2017.

4. Kantorová V, Wheldon MC, Ueffing P, Dasgupta AN. Estimating progress towards meeting women's contraceptive needs in 185 countries: A Bayesian hierarchical modelling study. PLoS Med. 2020;17(2):e1003026.

5. United Nations, Department of Economic and Social Affairs, Population Division. Family Planning and the 2030 Agenda for Sustainable Development: Data Booklet. (ST/ESA/SER.A/429). 2019.

6. United Nations, Department of Economic, \& Social Affairs, Population Division. Contraceptive Use by Method 2019: Data Booklet (ST/ESA/SER.A 435). 2019.

7. Asresie MB, Fekadu GA, Dagnew GW. Contraceptive use among women with no fertility intention in Ethiopia. PLoS One. 2020;15(6):e0234474. https://doi.org/10.1371/journal.pone.0234474.

8. Gebrecherkos K, Gebremariam B, Gebeyehu A, Siyum H, Kahsay G, Abay M. Unmet need for modern contraception and associated factors among reproductive age group women in Eritrean refugee camps, Tigray, North 
Ethiopia: a cross-sectional study. BMC Res Notes. 2018;11(1):851. https://doi. org/10.1186/s13104-018-3956-7.

9. Wulifan JK, Mazalale J, Kambala C, Angko W, Asante J, Kpinpuo S, et al. Prevalence and determinants of unmet need for family planning among married women in Ghana-a multinomial logistic regression analysis of the GDHS, 2014. Contracept Reprod Med. 2019:4(1):2.

10. Letamo G, Navaneetham K. Levels, trends and reasons for unmet need for family planning among married women in Botswana: a cross-sectional study. BMJ Open. 2015;5(3):1-11.

11. Gueye A, Speizer IS, Corroon M, Okigbo CC. Belief in family planning myths at the individual and community levels and modern contraceptive use in urban Africa. Int Perspect Sex Reprod Health. 2015;41(4):191.

12. Islam AZ. Factors affecting modern contraceptive use among fecund young women in Bangladesh: does couples' joint participation in household decision making matter? Reprod Health. 2018;15(1):112. https://doi.org/10.11 86/s12978-018-0558-8.

13. Belda SS, Haile MT, Melku AT, Tololu AK. Modern contraceptive utilization and associated factors among married pastoralist women in Bale eco-region, Bale Zone, South East Ethiopia. BMC Health Serv Res. 2017;17(1):194.

14. Debebe S, Limenih MA, Biadgo B. Modern contraceptive methods utilization and associated factors among reproductive aged women in rural Dembia District, Northwest Ethiopia: Community based cross-sectional study. Int J Reprod BioMed. 2017;15(6):367.

15. Eliason S, Awoonor-Williams JK, Eliason C, Novignon J, Nonvignon J, Aikins M. Determinants of modern family planning use among women of reproductive age in the Nkwanta district of Ghana: a case-control study. Reprod Health. 2014;11(1):65.

16. Ochako R, Mbondo M, Aloo S, Kaimenyi S, Thompson R, Temmerman M, et al. Barriers to modern contraceptive methods uptake among young women in Kenya: a qualitative study. BMC Public Health. 2015;15(1):1-9.

17. Corsi DJ, Neuman M, Finlay JE, Subramanian SV. Demographic and health surveys: a profile. Int J Epidemiol. 2012;41(6):1602-13.

18. Aliaga A, Ruilin R. Cluster optimal sample size for demographic and health surveys. In: 7th International Conference on Teaching Statistics-ICOTS, vol. 7; 2006. p. 2-7.

19. Von Elm E, Altman DG, Egger M, Pocock SJ, Gøtzsche PC, Vandenbroucke $J P$. The strengthening the reporting of observational studies in epidemiology (STROBE) statement: guidelines for reporting observational studies. Ann Intern Med. 2007;147(8):573-7. https://doi.org/10.7326/0003-4 819-147-8-200710160-00010.

20. Aviisah PA, Dery S, Atsu BK, Yawson A, Alotaibi RM, Rezk HR, et al. Modern contraceptive use among women of reproductive age in Ghana: Analysis of the 2003-2014 Ghana Demographic and Health Surveys. BMC Womens Health. 2018;18(1):141.

21. Ahinkorah BO, Seidu AA, Appiah F, Budu E, Adu C, Aderoju YBG, et al. Individual and community-level factors associated with modern contraceptive use among adolescent girls and young women in Mali: a mixed effects multilevel analysis of the 2018 Mali demographic and health survey. Contracept Reprod Med. 2020;5(1):1-12.

22. Ahinkorah BO. Predictors of modern contraceptive use among adolescent girls and young women in sub-Saharan Africa: a mixed effects multilevel analysis of data from 29 demographic and health surveys. Contracept Reprod Med. 2020;5(1):1-12.

23. Ejembi CL, Dahiru T, Aliyu AA. DHS working papers; 2015.

24. Lasong J, Zhang Y, Gebremedhin SA, Opoku S, Abaidoo CS, Mkandawire T, et al. Determinants of modern contraceptive use among married women of reproductive age: a cross-sectional study in rural Zambia. BMJ Open. 2020; 10(3):e030980. https://doi.org/10.1136/bmjopen-2019-030980.

25. United Nations 1999, Standard country or area codes for statistics use, 1999 (Revision 4), viewed May 23 2020, https://unstats.un.org/unsd/publications/ catalogue?select|D=109. Accessed 23 Nov 2020.

26. Chikandiwa A, Burgess E, Otwombe K, Chimoyi L. Use of contraceptives, high risk births and under-five mortality in Sub Saharan Africa: evidence from Kenyan (2014) and Zimbabwean (2011) demographic health surveys. BMC Womens Health. 2018;18(1):173.

27. Mturi A, Joshua K. Falling fertility and increase in use of uontraception in Zimbabwe. Afr J Reprod Health. 2011;15(2):31-44.

28. Adebowale SA, Adeoye IA, Palamuleni ME. Contraceptive use among Nigerian women with no fertility intention: interaction amid potential causative factors. Afr Popul Stud. 2013;27(2):127-39. https://doi.org/10.11564/27-2-435.
29. Ba DM, Ssentongo P, Agbese E, Kjerulff KH. Prevalence and predictors of contraceptive use among women of reproductive age in 17 sub-Saharan African countries: a large population-based study. Sexual Reprod Healthcare. 2019;21:26-32. https://doi.org/10.1016/j.srhc.2019.06.002.

30. Ahmed M, Seid A. Association between exposure to mass media family planning messages and utilization of modern contraceptive among urban and rural youth women in Ethiopia. Int J Women's Health. 2020;12:719-29. https://doi.org/10.2147/IJWH.S266755.

31. Measurement L, Team EPN. Evaluation of the Nigerian urban reproductive health initiative (NURHI) program. Stud Fam Plan. 2017;48:253-68.

32. Jacobs J, Marino M, Edelman A, Jensen J, Darney B. Mass media exposure and modern contraceptive use among married west African adolescents. Eur J Contracept Reprod Health Care. 2017;22(6):439-49. https://doi.org/10.1 080/13625187.2017.1409889.

33. Islam MM, Hasan AS. Mass media exposure and its impact on family planning in Bangladesh. J Biosoc Sci. 2020;32(4):513-26.

34. Avong NH. Relationship between religion and use of modern contraceptives among the Atyap in Kaduna state, Nigeria. Res Humanit Soc Sci. 2012;2(8):82-9.

35. Viswan SP, Ravindran TS, Kandala NB, Petzold MG, Fonn S. Sexual autonomy and contraceptive use among women in Nigeria: findings from the demographic and health survey data. Int J Women's Health. 2017;9:581-90. https://doi.org/10.2147/IJWH.S133760

36. Musa A, Assefa N, Weldegebreal F, Mitiku H, Teklemariam Z. Factor associated with experience of modern contraceptive use before pregnancy among women who gave birth in Kersa HDSS, Ethiopia. BMC Public Health. 2016;16(1):614. https://doi.org/10.1186/s12889-016-3292-6.

37. Lakew Y, Reda AA, Tamene H, Benedict S, Deribe K. Geographical variation and factors influencing modern contraceptive use among married women in Ethiopia: evidence from a national population based survey. Reprod Health. 2013;10(1):52. 24067083. https://doi.org/10.1186/1742-4755-10-52.

38. Crissman HP, Adanu RM, Harlow SD. Women's sexual empowerment and contraceptive use in Ghana. Stud Fam Plan. 2012;43(3):201-12. https://doi. org/10.1111/j.1728-4465.2012.00318.x PMID: 23185863.

39. Alsaleem MA, et al. Contraceptive use as limiters and spacers among women of reproductive age in southwestern, Saudi Arabia. Saudi Med J. 2018;39(11): 1109. https://doi.org/10.15537/smj.2018.11.22817 PMID: 30397710

40. Hani RA, Peleg R, Freud T, Treister-Goltzman Y. Knowledge, attitudes and contraceptive use among Muslim Bedouin women in southern Israel. Health Soc Care Commun. 2020;1(2):1-8

41. Palamuleni ME. Socio-economic and demographic factors affecting contraceptive use in Malawi. Afr J Reprod Health. 2013;17(3):91-104. 24069771.

42. Nyarko SH. Spatial variations and socioeconomic determinants of modern contraceptive use in Ghana: a Bayesian multilevel analysis. PLoS One. 2020; 15(3):e0230139. https://doi.org/10.1371/journal.pone.0230139.

43. Muanda MF, Ndongo GP, Messina L, Bertrand JT. Barriers to modern contraceptive use in rural areas in DRC. Cult Health Sex. 2017;19(9):1011-23.

\section{Publisher's Note}

Springer Nature remains neutral with regard to jurisdictional claims in published maps and institutional affiliations.

Ready to submit your research? Choose BMC and benefit from:

- fast, convenient online submission

- thorough peer review by experienced researchers in your field

- rapid publication on acceptance

- support for research data, including large and complex data types

- gold Open Access which fosters wider collaboration and increased citations

- maximum visibility for your research: over $100 \mathrm{M}$ website views per year

At $\mathrm{BMC}$, research is always in progress.

Learn more biomedcentral.com/submission 